\title{
Retour sur « Les Costumes du Sud de la Laponie »
}

\section{Yves Delaporte}

\section{OpenEdition}

Journals

Édition électronique

URL : https://journals.openedition.org/tc/5116

DOI : $10.4000 /$ tc. 5116

ISSN : 1952-420X

\section{Éditeur}

Éditions de l'EHESS

\section{Édition imprimée}

Date de publication : 30 juin 2010

Pagination : 628-630

ISSN : 0248-6016

\section{Référence électronique}

Yves Delaporte, «Retour sur « Les Costumes du Sud de la Laponie » », Techniques \& Culture [En ligne], 54-55 | 2010, mis en ligne le 30 juin 2013, consulté le 29 septembre 2022. URL : http:// journals.openedition.org/tc/5116 ; DOI : https://doi.org/10.4000/tc.5116 

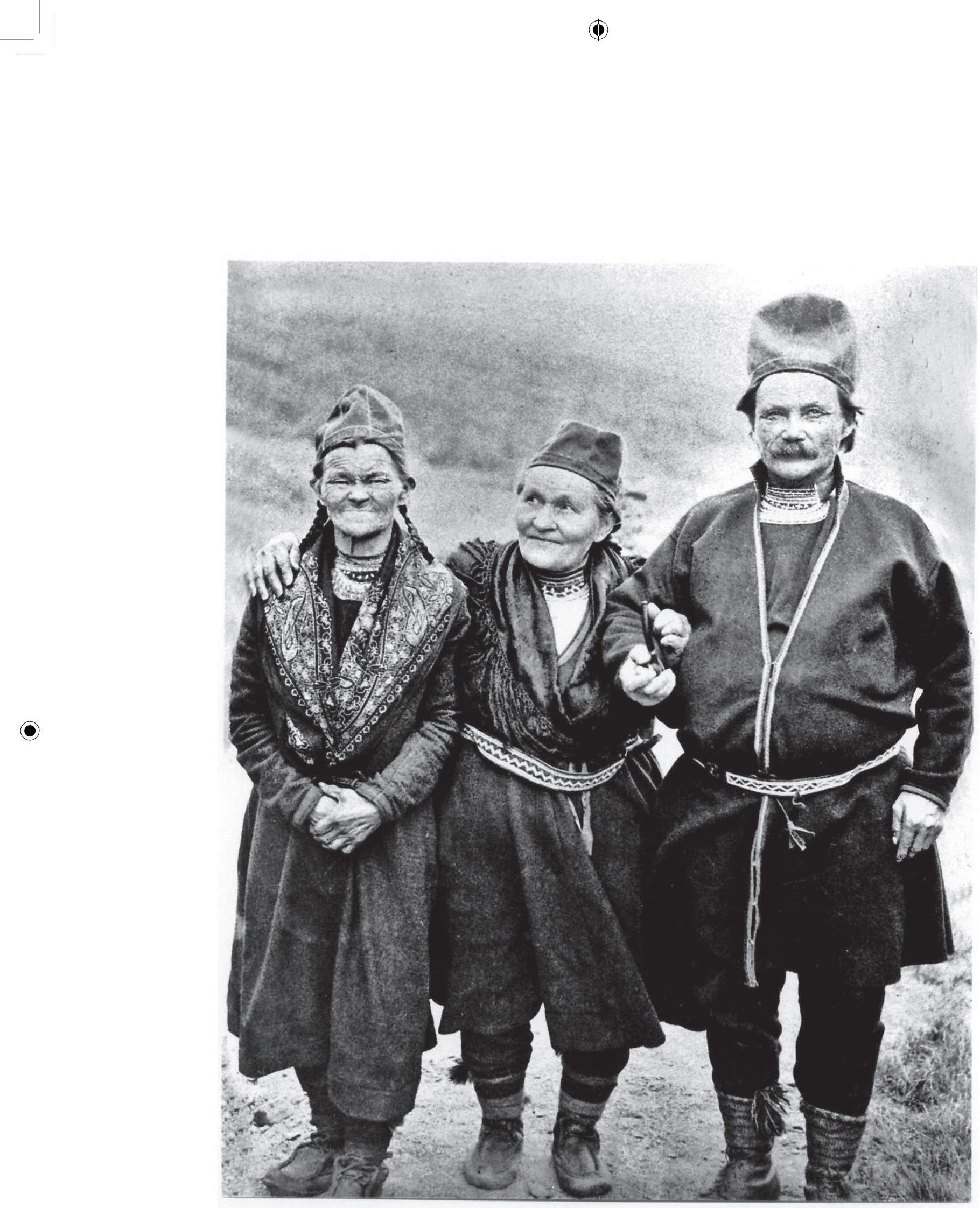

$\oplus$ 


\section{« Les Costumes du Sud de la Laponie »}

Quittant en 1978 les rivages de l'Océan glacial arctique où j'avais achevé l'étude de la variation régionale du vêtement lapon le plus septentrional, j'ai pris mon bâton de pèlerin et suis parti à l'aventure vers le sud de la Norvège. À l'opposé de mon terrain de prédilection, la commune de Kautokeino où les pasteurs vivant de l'élevage du renne sont largement majoritaires, les Lapons du Sud sont très minoritaires, petits fermiers mêlés à la population norvégienne au point d'être à peu près invisibles. Avant d'interroger ces Lapons sur leurs costumes, depuis longtemps abandonnés comme habits quotidiens, il fallait donc les trouver : j'ai pour cela été conduit à faire du porte-à-porte sur un trajet de mille kilomètres, allant de village en village pour m'enquérir à la ronde de l'existence de maisons qui pourraient abriter des familles lapones. Le chercheur a parfois besoin d'un coup de pouce du hasard : c'est la chance que j'ai eue lorsque cette méthode d'enquête pour le moins insolite m'a conduit chez Nils Kappfjell, un éleveur de rennes âgé de soixante-dix ans, qui m'a livré tout de go un système symbolique que rien ne laissait soupçonner, sinon quelques très rares indications éparses dans la littérature scandinave. Ma première réaction a été de méfiance : à la fois l'un des derniers grands éleveurs du Sud de la Laponie norvégienne, très attaché aux traditions, autodidacte travaillant à l'élaboration d'un dictionnaire lapon-norvégien, intervenant fréquemment dans le débat public sur la situation de la minorité lapone, Nils pouvait être suspecté de me livrer davantage une construction trompeusement harmonieuse qu'une description fidèle de faits réels. Que les mêmes informations me soient fournies dans des hameaux voisins pouvait être attribué à l'influence de cette forte personnalité. L'enquête que j'ai étendue l'année suivante à plusieurs provinces suédoises m’a montré qu'il n'en était rien. Découvrir des résultats si nouveaux dans une région passée au peigne fin par l'ethnographie scandinave prouve que l'on n'en a jamais fini avec le terrain. 
Le travail présenté dans cet article a eu une suite en 1979 : en remontant vers le nord, toujours village après village et hameau après hameau, mais cette fois en territoire suédois, d'autres faits, de plus en plus ténus, sont venus apporter la preuve de l'existence d'un ancien système symbolique inscrit dans l'ensemble de la Laponie. Située sur le cercle polaire, à mi-chemin du nord et du sud de la Laponie, la commune de Jokkmokk m'est apparue comme une région charnière, la dernière où le système symbolique mis en évidence au sud demeure conscient. Au nord du cercle polaire, ce ne sont plus que des traces. La fonction sémiotique du vêtement lapon est donc un trait gradient dont l'importance varie dans l'espace de manière ordonnée.

Loutil conceptuel qui m'a guidé tout au long de cette enquête est celui de pertinence. Dans le fouillis des variations régionales, locales, familiales, individuelles formant un presque inextricable écheveau, il s'agissait de repérer les plus minimes détails rattachés au point de vue qui avait été adopté, celui de la pertinence sémiologique. Revenu à Kautokeino même, mon point de départ situé à proximité du Cap Nord, je retrouvai dans les coiffures le rouge féminin et le bleu masculin, ce dernier étant masqué par une exubérante ornementation à dominante rouge qui relève d'autres pertinences, l'esthétique et la compétition sociale. Tout cela a été synthétisé dans une thèse de doctorat d'État, Le vêtement lapon. Formes, fonctions, évolution (Delaporte 2004 [1990]).

Photo d'ouverture : village de Majavatn (Nordland, Norvège), vers 1920

Album de famille de Lars Larsen Vestfjell. Cl. Y. Delaporte

Yves Delaporte 